\title{
Menstrual Mood Disorders are Associated with Blunted Sympathetic Reactivity to Stress
}

\author{
Rebecca R. Klatzkin, Ph.D. ${ }^{1}$, Adomas Bunevicius, M.D., Ph.D. ${ }^{2}$, Catherine A. Forneris, \\ Ph.D. ${ }^{2}$, and Susan Girdler, Ph.D. ${ }^{2}$ \\ ${ }^{1}$ Department of Psychology, Rhodes College, Tennessee, USA \\ ${ }^{2}$ Department of Psychiatry, University of North Carolina at Chapel Hill, North Carolina, USA
}

\section{INTRODUCTION}

The burden of mood disorders upon women in the United States is substantial, with a lifetime prevalence rate of approximately $25 \%$ in adult women compared to $17 \%$ in adult men [1]. This gender difference is further magnified when taking into consideration the exclusivity of menstrually related mood disorders (MRMDs) to women only. Menstrually related mood disorders represent a constellation of clinically significant affective, behavioral, and physical symptoms, along with functional impairment, occurring in the late luteal phase of the menstrual cycle and remitting shortly after the onset of menses [2, 3]. Among premenopausal women, approximately $30 \%$ experience some form of a MRMD, including the $8 \%$ of women who suffer from premenstrual dysphoric disorder (PMDD), the most severe MRMD [4-6]. The disability adjusted life years lost due to a MRMD is within the same magnitude as other affective and anxiety disorders, such as major depressive disorder (MDD) and posttraumatic stress disorder [5, 7], and is associated with a significant risk of attempted suicide [8].

Despite more than 65 years of research investigating MRMDs, underlying pathophysiological mechanisms remain elusive. There is recent evidence that psychosocial history may provide the context for distinct pathophysiological phenotypes in MRMDs. For example, women with both a MRMD and a history of sexual or physical abuse show a unique thyroid axis and adrenergic profile relative to women with a MRMD, but no history of abuse [9-11].

A history of depression provides another context of vulnerability that may be of particular relevance to MRMD. A history of depression and other affective disorders has been reported in 30-70\% of women with a MRMD [8, 12-14]. Not only are women with a MRMD more likely than non-MRMD women to have experienced a prior episode of depression [13,15], but a MRMD also predicts the development of major depressive disorder (MDD) [16-18]. The comorbid relationship between MDD and MRMDs has fueled studies investigating the nosology of the two disorders. While MDD and MRMDs do share genetic and

(C) 2013 Elsevier Inc. All rights reserved.

Corresponding author: Rebecca Klatzkin, Ph.D., Rhodes College, 2000 North Parkway, Memphis, TN 38112, Tel.: +1 901843 3516; fax: +1 901843 3427. klatzkinr@ rhodes.edu.

Publisher's Disclaimer: This is a PDF file of an unedited manuscript that has been accepted for publication. As a service to our customers we are providing this early version of the manuscript. The manuscript will undergo copyediting, typesetting, and review of the resulting proof before it is published in its final citable form. Please note that during the production process errors may be discovered which could affect the content, and all legal disclaimers that apply to the journal pertain.

This work was done at Department of Psychiatry, University of North Carolina at Chapel Hill, North Carolina, USA. 
environmental risk factors to a modest degree [19], it has been argued that MRMDs are a distinct entity when compared to other mood disorders in terms of cognitive factors, physiological biomarkers, and treatment outcomes [14, 20].

Examination of stress responsive pathways may shed light on unique versus shared stress phenotypes in MRMD compared with other mood disorders, since both MRMDs and other mood disorders are associated with increased daily stress [21-24] and are either triggered or exacerbated by stressful life events [19,25-27]. Although studies examining stress responses in women with a MRMD have been scant, and results mixed [e.g. 28], the majority of evidence points toward hypo-responsiveness to challenge in both the hypothalamic pituitary adrenal (HPA) axis [22, 28-33] and the sympathetic nervous system (SNS) [21, 22, 35] in women with a MRMD relative to women without a MRMD [36].

While hyperactivity of the HPA and SNS stress axes is consistently found in patients with current melancholic depression [37-47], studies of euthymic patients with a history of depression have produced conflicting results, showing hyperactivity [35, 48-53], hypoactivity $[54-56]$ or no differences $[54,56]$ relative to never depressed controls in measures reflecting SNS or HPA axes. Stress response dysregulation in those with a history of depression, as found in the majority of previous studies, may be clinically relevant, since a recent study in remitted MDD patients reported HPA-axis dysregulation in response to a mild stressor may predict the development of future depressive symptoms [57].

Few studies have directly compared MRMD women with women who have suffered from other mood disorders for stress reactivity phenotypes. The results of such investigations may be relevant to understanding not only the pathophysiology of mood disorders in general, but particularly that of MRMDs. The primary aim of the present study was to compare women with MRMD to non-MRMD women, approximately half of whom had a history of depression, and to investigate whether the hypoactive responses to stressors previously reported in women with a MRMD reflect a unique phenotype of MRMDs or could more parsimoniously be explained by a history of depression in this population. A secondary, exploratory aim was to investigate the relationship of stress reactivity to premenstrual symptomatology in order to examine any potential pathophysiological relevance of stress reactivity to mood disorders.

\section{METHODS}

\section{Participants}

The sample of 126 women (19-51 years of age) who comprise this report were recruited via newspaper, radio, or posted advertisements targeting either women with severe premenstrual symptoms or women without premenstrual symptoms. The final sample of participants was composed of four groups: 1) Women with a MRMD without a history of depression ( $\mathrm{n}=$ 37); 2) Women with a MRMD plus a history of depression $(\mathrm{n}=26)$; 3) Women without a MRMD and without or depression $(\mathrm{n}=43)$; and 4$)$ Women without a MRMD but with a history of depression $(n=20)$.

Participants with a current Axis I psychiatric disorder were excluded (based on interview, see below), but referred for treatment. Women who were pregnant or breastfeeding, had irregular menstrual cycles, taking prescription medication (including oral contraceptives and psychotropics), had a cardiovascular disorder, a current chronic or acute pain condition, an endocrine disorder (including diabetes or thyroid disorder), or other chronic medical illness, were also excluded from the final sample. A diagnosis of a history of depression was based on a structured clinical interview (see below). The never depressed groups were free of any lifetime depressive illness, including minor depression, dysthymia and adjustment disorder 
with depressed mood. The protocol was approved by the institution's Institutional Review Board, and all participants provided informed, written consent. Participants received $\$ 100$ compensation.

\section{Procedures}

Screening and Enrollment-During the enrollment session, informed consent was obtained, as was a series of stethoscopic blood pressures and a medical history. Participants were instructed on the Daily Record of Severity of Problems (DRSP) form [58], which they were asked to complete daily for 2-3 consecutive menstrual cycles in order to confirm the diagnosis of MRMD. Upon completion of the DRSP ratings, a comprehensive psychiatric history was obtained.

Confirmation of MRMD Diagnosis-MRMD and non-MRMD status was confirmed prospectively using the DRSP [58]. The DRSP forms were mailed back weekly in order to discourage retrospective reporting. The DRSP consists of 24 items and allows for the quantification of the severity of physical, emotional and behavioral symptoms of MRMD as well as functional impairment using a 6 -point scale $(1=$ absent, $2=$ minimal, $3=$ mild, $4=$ moderate, $5=$ severe and $6=$ extreme). A diagnosis of MRMD was based on the following criteria: (1) at least a 30\% decrease in emotional symptom severity from the seven luteal phase days preceding menses compared with follicular phase days 4-10; (2) a rating of emotional symptoms as moderate, severe or extreme on at least two of the seven premenstrual days; (3) remission of symptoms shortly after the onset of menses followed by a clear symptom free period ( $\geq 6$ consecutive days) during the early-to-mid follicular phase and (4) criteria 1-3 met in at least two menstrual cycles [58,59]. Since we did not require the arbitrary 5 or more different symptoms during the luteal phase as required by the DSMIV for the diagnosis of premenstrual dysphoric disorder (PMDD), we describe our sample as women with a menstrual mood disorder (MRMD). However, 53 (84\%) of the women in this report did, in fact, display 5 or more symptoms premenstrually that met severity and remission criteria above (criteria 2 and 3 ) and would therefore meet DSM-IV criteria for PMDD.

Women without a MRMD met the following criteria: (1) no more than minimal emotional symptoms occurring on fewer than three days during the premenstrual week; (2) less than a $30 \%$ decrease in emotional symptom severity from the luteal to the follicular phase; and (3) these criteria met in at least two menstrual cycles.

A total of 232 women were prospectively evaluated for MRMD, with 78 (33\%) meeting prospective criteria consistent with other reports [21]. A total of 85 entered as non-MRMD controls, with 79 (93\%) meeting prospective control criteria. Following the prospective diagnostic phase, 14 MRMD women did not enter into the experimental phase of the study (8 lost to follow-up, 5 declined, and 1 was withdrawn) and 16 non-MRMD women did not enter into the experimental phase of the study (9 lost to follow-up, 1 declined, and 6 were not tested due to laboratory relocation at that time). One additional woman with a MRMD was enrolled in the study, but was not included in the analyses because no SNS data was collected due to equipment error. Consequently 63 women with MRMD (26 with a history of depression) and 63 non-MRMD women (20 with a history of depression) comprise the sample for this report.

Diagnosis of Psychiatric Disorders-The MINI Structured Psychiatric Interview [60] was used to evaluate all women for current and past Axis I psychiatric disorders. All diagnoses were based on a consensus diagnostic session with a clinical psychologist. Since lifetime histories of mood disorders are prevalent in women with a MRMD [13, 15], one 
year in full remission was required for mood disorders, while for other Axis I disorders three years in remission was required.

Test Session-All laboratory sessions took place during the luteal phase of the menstrual cycle, 5-12 days after home urine ovulation testing indicated the luteinizing hormone surge that indicates ovulation (corresponding to days $18-25$ of an idealized 28 day cycle). The luteal (symptomatic) phase was the only phase studied since there is little consistent evidence that menstrual cycle phase influences blood pressure (BP) or heart rate (HR) reactivity in healthy controls $[61,62]$ or $\mathrm{BP}, \mathrm{HR}$, and neuroendocrine differences between MRMD and non-MRMD groups at rest or during stress [21, 22, 32, 34].

All laboratory testing began between the hours of 7:00 am and 9:30 am. The laboratory visit lasted approximately three hours and thirty minutes and followed a fixed sequence. Although the entire testing sequence is reported here, we focus solely on the results of the stress testing portion of the protocol in the present report.

The order of testing was as follows: 1) Instrumentation for BP monitoring (Suntech 4240 Exercise BP monitor) and stethoscopic BP assessments to ensure reliable cuff placement and microphone position; 2) IV setup and recovery; 3) Baseline 1 Rest; 4) Beck Depression Inventory-II (BDI-II) and Spielberger State Anxiety Inventory (SAI); 5) Pain Testing; 6) Recovery; 7) Baseline 2 Rest; 8) Trier Social Stress Test (TSST).

Intravenous Blood Draw Setup: A research nurse inserted a butterfly needle into a forearm vein. A non-heparinized, multi-stop-cock system was employed, to allow the nurse to draw blood samples without the added stress involved in multiple venipunctures. Once the needle was in place, a curtain was drawn to prevent the participant from viewing blood sampling. A 15 minute recovery period followed the intravenous blood draw setup.

Baseline 1 Rest: Participants rested quietly for 10 minutes in order to serve as the baseline for pain testing. Depression and state anxiety were measured at the end of this rest period using the BDI-II and SAI.

Pain Testing: Participants were exposed to two pain tests: the submaximal effort tourniquet procedure and the hand cold pressor. Results and details on the pain testing procedure are reported elsewhere [63].

Recovery: A five minute recovery period followed each pain task.

Baseline 2 Rest: Following the recovery period, quiet rest ensued for an additional 10 minutes, serving as a baseline from which to calculate SNS reactivity. Blood pressure and HR measures were taken at minutes 1, 3, 6, and 9 and averaged. Blood was sampled at minute 10 for baseline levels of norepinephrine (NE).

The Trier Social Stress Test (TSST): A modified version of the TSST [64] was employed (modified to include serial addition as opposed to serial subtraction). The TSST is a stress test which reliably induces large and consistent cardiovascular responses [64-66]. The TSST involves four components: 1) Pre-Task Instructions (5 minute) during which time participants are told that the first task entails giving a speech that will serve as an interview for their ideal job and are then introduced to the 'selection committee' who will later listen to their job talk. Participants are also given the instructions for the mental arithmetic task. 2) Speech Preparation Period (5 minute): Participants were told that they should imagine that they are applying for their ideal job and were then left alone for 5 minutes to prepare their talk describing why they would be the ideal candidate for the position; 3) Job Speech (5 
minute): Immediately following the preparation period, the selection committee returned to the testing room and asked the participant to deliver her talk describing to the committee why she would be the perfect applicant for the position. If the participant finished before 5 minutes, the committee responded in a standardized way, with prepared questions to ensure that the participant spoke for the entire period; and 4) Paced Auditory Serial Addition Test (PASAT; [67]) (8.5 minutes): Involves the tape recorded presentation of numbers from $1-$ 9. Participants are to add each number presented on the tape to the immediately preceding number and to state the answer out loud to the committee. There are four series of numbers, with progressively shorter inter-digit intervals $(2.4,2.0,1.6$, and 1.2 seconds). The experimenter remained in the room to monitor performance.

Task Assessments: Task assessment questionnaires were administered after the cessation of the TSST. Using a visual analog scale, the participants rated: 1) how difficult they found the task; 2) how tense they were during the task; 3 ) how well they were able to concentrate during the task; and 4) how much effort they put into the task.

Cardiovascular Sampling During the TSST: All measurements took place while participants were in a comfortable seated position. Blood pressure and HR measures were taken at minutes 1, 3, and 5 of the Speech Preparation Period, minutes 1, 3, and 5 of the Job Speech, and minutes 2, 4, 6, and 8 of Serial Addition and averaged to constitute task levels. Norepinephrine was sampled at the end of minute 2 of Speech and minute 2 of Serial Addition since catecholamines peak within the first minutes of stress and have a short halflife (3 min) [68].

\section{Measurements}

Physiologic recording procedures-The Suntech Exercise BP monitor, Model 4240 (SunTech Medical Instruments, Inc., Raleigh, NC) provided automated measurement of systolic BP, diastolic BP and HR during the sessions. Prior to initiating the Baseline 1 Rest period, five standard stethoscopic blood pressures were taken simultaneously with the automated pressures in order to ensure correct microphone placement and cuff positioning.

Impedance cardiography was used to permit non-invasive monitoring of cardiac performance [69]. A custom-designed impedance cardiograph (HIC-100, Bioimpedance Technology Inc., Model 100, Chapel Hill, NC, USA) was used in conjunction with a tetrapolar band electrode configuration to record impedance $\mathrm{dZ} / \mathrm{dt}$ and $\mathrm{Z} 0$ signals. Impedance and electrocardiogram signals were processed on-line by specialized computer software (BIT, Chapel Hill, NC) with subsequent manual editing to improve accuracy. For each minute of interest, a $30 \mathrm{~s}$ continuous sample of waveforms (obtained concurrently with BP) was processed to generate an ensemble-averaged cardiac cycle, from which stroke volume (SV) was determined by means of the Kubicek et al. [70] equation and HR was determined by the mean interbeat interval. Cardiac output $(\mathrm{CO})$ and total peripheral resistance (TPR) for these same minutes were then calculated using standard formula [69]. Since we found that, in those with no history of depression, women with a MRMD had a greater BMI than women without a MRMD (see results), SV, CO and TPR were adjusted for body surface area (BSA), yielding stroke index (SVI), cardiac index (CI), and total peripheral resistance index (TPRI). BSA was calculated using the following formula: BSA $\left(\mathrm{m}^{2}\right)=\mathrm{W}(\mathrm{kg})^{0.425} \times \mathrm{H}(\mathrm{cm})^{0.725} \times .007184$.

Norepinephrine concentrations-Plasma levels of NE were determined using the highpressure liquid chromatography with electrochemical detection (HPLC-ECD) technique. The lower limit of quantification is $2.5 \mathrm{pg} / \mathrm{ml}$, and the intra- and inter-day coefficients of variation are less than $10 \%$. 


\section{DATA ANALYSIS}

\section{Demographics}

Group differences in demographic factors, state anxiety and depression scores, as well as baseline SNS factors were examined using a 2 (MRMD: yes vs. no) $\times 2$ (History of Depression: yes vs. no) ANOVA for continuous variables and chi square analyses for dichotomous variables as appropriate. For women with histories of depression, MRMD and non-MRMD groups were compared on months since last major depressive episode with a one way ANOVA. Where significant interactions emerged, simple effects analyses performed separately in prior depression or MRMD groups were conducted to explore the source of the interaction.

\section{Daily Symptom Ratings}

For each of the 24 DRSP symptoms, a follicular (days 4 through 10) and luteal (days -7 through -1 before menses) phase average was calculated for cycle one. Average premenstrual symptom severity from the first menstrual cycle only was analyzed in order to avoid the confounding effect that repeated symptom monitoring over several months may have on symptoms [71]. Next, each symptom was placed into one of five core symptom categories [58]: 1) Somatic (fatigue, breast tenderness, breast swelling or bloating, headache, joint or muscle pain); 2). Depression: (depressed, hopeless, worthless or guilty, slept more, trouble sleeping, overwhelmed); 3) Anger/Irritability: (anger or irritability, conflict); 4) Anxiety: (anxiety); and 5) Impairment: (less productivity or efficiency, interference with hobbies or social activities, interference with relationships), and averaged to yield one total follicular and luteal score for each of the five core categories.

Women were assessed for differences in the five core symptom categories using a 2 $($ MRMD) $\times 2$ (History of Depression) $\times 2$ (Menstrual Cycle Phase) repeated measures ANOVA with Menstrual Cycle Phase as the repeated factor. Where significant interactions emerged, simple effects analyses conducted separately in prior depression or MRMD groups were conducted to explore the source of the interaction.

\section{Sympathetic Nervous System (SNS) Stress Reactivity}

Group differences in baseline measures were analyzed using a $2($ MRMD) $\times 2$ (History of Depression) ANOVA. Next, cardiovascular and NE stress responsivity were examined by calculating delta scores (Stress task - Baseline) and performing a 2 (MRMD) $\times 2$ (History of Depression $) \times 2$ (Stress Task: Speech vs. Math) repeated measures ANOVA with stress task as the repeated factor.

\section{Sympathetic Nervous System (SNS) Stress Reactivity and Premenstrual Symptom Severity Ratings}

In order to explore the role of sympathetic stress reactivity in premenstrual symptom severity, exploratory analyses examining the relationship between SNS stress reactivity and luteal phase symptom severity ratings for the five core symptom categories were conducted using Pearson's correlational analyses. In order to reduce Type I error rates, and because of the relatively small cells sizes, we created a mean reactivity score for each dependent measure (averaging speech and math reactivity), conducted these analyses in the entire sample of women, and restricted these analyses to SNS measures that were found to differ by MRMD status or history of depression (see Results). Consequently, we examined the relationship between daily symptom severity ratings and $\mathrm{HR}$, DBP, NE, and CI reactivity to stress. 


\section{Subjective Response to Stress}

The participants' experiences of each stress task (difficulty, tension, inability to concentrate, effort) as measured by the task assessment questionnaire was analyzed by MRMD and history of depression status using a $2($ MRMD) $\times 2$ (History of Depression) ANOVA. The analyses were performed separately for the speech and math tasks and for each of the 4 items on the task assessment. Higher scores indicate greater difficulty, tension, inability to concentrate, and effort.

\section{RESULTS}

\section{Demographics and Baseline Measures}

As summarized in Table 1, no group differences emerged for age, BMI, or minority race (ps $>.05)$. Women with a MRMD had higher luteal phase depression $(\mathrm{F}(1,122)=28.0, \mathrm{p}<$. $001)$ and state anxiety ratings $(\mathrm{F}(1,122)=7.9, \mathrm{p}<.01)$ than women without a MRMD. All but one participant in the groups with a history of depression had a history of major depressive disorder; the other woman had a history of dysthymia. Women with and without a MRMD did not differ in months in remission from their most recent depressive episode (all ps >.05). Women with histories of depression were more likely to have a history of anxiety disorders $\left(\chi^{2}(1)=15.2, p<.001\right)$, substance abuse $\left(\chi^{2}(1)=13.3, p<.01\right)$, and suicidality $\left(\chi^{2}(1)=21.1, \mathrm{p}<.001\right)$ than women without a history of depression.

There were no significant group differences involving resting cardiovascular measures (Table 2).

\section{Daily Symptom Ratings}

As expected, MRMD $\times$ Menstrual Cycle Phase interactions were present for all core symptom categories assessed via the DRSP [58] [somatic: $\mathrm{F}(1,122)=55.1, \mathrm{p}<.001$, depression: $\mathrm{F}(1,122)=72.5, \mathrm{p}<.001$, anger/irritability: $\mathrm{F}(1,122)=135.8, \mathrm{p}<.001$, anxiety: $\mathrm{F}(1,122)=69.72, \mathrm{p}<.001$, and impairment: $\mathrm{F}(1,122)=62.3, \mathrm{p}<.001$ ], reflecting both a significant phase effect on symptoms in MRMD women only (ps <.001) and the greater MRMD-related differences for all symptom categories in the luteal phase that were not evident in the follicular phase (ps <.001) (Figure 1). Additionally, a History of Depression $\times$ Menstrual Cycle Phase interaction emerged for impairment symptoms ( $\mathrm{F}(1$, $122)=5.5, \mathrm{p}<.05$ ). Simple effects analyses revealed that women with a history of depression reported greater impairment than women with no history of depression in the luteal phase $(\mathrm{t}(124)=2.3, \mathrm{p}<.05)$.

\section{Sympathetic Nervous System (SNS) Stress Reactivity}

Both the speech and math task induced significant increases in HR, SBP, DBP, CI reactivity and decreases in TPRI reactivity $(\operatorname{Fs}(1,115-119)=19.4-503.6$, ps <.001). Stroke volume index did not change significantly as a result of the stress tasks. Despite the absence of diagnosis-related differences in any cardiovascular and NE measures at baseline rest (Table 2 ), women with a MRMD had blunted $\mathrm{HR}(\mathrm{F}(1,118)=8.7$, $\mathrm{p}<.01)$ and $\mathrm{CI}(\mathrm{F}(1,116)=9.1$, $\mathrm{p}<.01)$ reactivity to stress relative to women without a MRMD, regardless of depression histories (Figures 2 and 3). There was also a MRMD $\times$ History of Depression interaction for NE stress reactivity $(\mathrm{F}(1,100)=4.1, \mathrm{p}<.05)$ and a trend for DBP stress reactivity $(\mathrm{F}(1$, $115)=3.0, \mathrm{p}=.09)$. Women with a MRMD showed blunted $\mathrm{DBP}(\mathrm{F}(1,75)=11.37, \mathrm{p}<.01)$ and $\mathrm{NE}(\mathrm{F}(1,65)=9.59, \mathrm{p}<.01)$ responses to stress relative to women with no MRMD, but only in women with no history of depression (Figures 4 and 5). There were no significant effects involving SBP, SVI or TPRI stress reactivity (Table 2). 


\section{Sympathetic Nervous System (SNS) Stress Reactivity in Relation to Daily Symptom Ratings}

In the sample as a whole, blunted stress reactivity predicted greater luteal phase symptom severity. Specifically, blunted HR and CI reactivity to stress predicted greater premenstrual depression ( $\mathrm{rs}=-0.20$ and -0.23 , respectively, $\mathrm{ps}<.05$ ), anger/irritability ( $\mathrm{rs}=-0.19$ and -0.21 , respectively, ps $<.05$ ), and anxiety ( $r s=-0.25$ and -0.24 , respectively, ps $<.05$ ). There were no statistically significant relationships involving DBP or NE reactivity and premenstrual symptomatology.

\section{Subjective Responses to Stress}

Women with a MRMD, regardless of depression history, reported greater difficulty during speech stress $(\mathrm{F}(1,117)=8.3, \mathrm{p}<.01)$ and inability to concentrate during math stress $(\mathrm{F}(1$, $118)=8.7, \mathrm{p}<.01)$ than women without a MRMD. Women with a history of depression, regardless of MRMD diagnosis, reported greater difficulty during math stress $(\mathrm{F}(1,118)=$ $3.9, \mathrm{p}=.05)$ than women without a history of depression. A MRMD $\times$ History of Depression interaction emerged for tension during the speech task $(\mathrm{F}(1,117)=4.8, \mathrm{p}<.05)$, since only in women with a history of depression did women with a MRMD report greater tension $(\mathrm{F}(1,117)=12.4, \mathrm{p}<.01)$ than women without a MRMD.

No statistically significant group differences in subjective effort ratings were found for the speech or math stress tasks.

\section{DISCUSSION}

The chief findings of this investigation were: 1) women with a MRMD showed blunted myocardial (HR and CI) reactivity to mental stress compared to non-MRMD women, irrespective of histories of depression; 2) women with a MRMD showed blunted NE and DBP stress reactivity relative to women with no MRMD, but only when no history of depression was present; 3 ) blunted HR and CI stress reactivity predicted greater premenstrual symptom severity. These results suggest that MRMDs are associated with blunted myocardial reactivity to mental stress, while for NE and DBP, this hypo-reactivity in MRMD women is seen only in women with no history of depression. Nonetheless, these results support the contention that a blunted SNS reactivity profile represents a unique phenotype of MRMDs that is not explained by a history of depression. Moreover, the preliminary results suggest that the phenotypic profile of blunted myocardial stress reactivity may be pathologically relevant since it predicts heightened luteal phase affective symptom severity.

Blunted cardiovascular reactivity to stress in women with MRMDs has been previously documented, though most studies did not control for depression histories [21, 22]. Blunted myocardial stress reactivity in MRMDs would be consistent with alterations in the myocardial $\beta 1$-adrenergic receptors ( $\beta$-AR), which mediate both inotropic and chronotropic heart activity, and which have been previously implicated in MRMDs as suggested by several lines of evidence. First, estrogen and progesterone, which are pathophysiologically relevant in MRMDs [72], modulate the activity and expression of $\beta$-ARs in animal models [73-75]. In humans, the density of lymphocytic $\beta 2$-ARs vary with menstrual cycle phase [76]. Second, the clinical relevance of $\beta$-ARs to MRMDs was suggested by the findings of Gurguis et al. [77] who observed diagnostic differences in $\beta 2$-AR density in MRMD relative to non-MRMD women, and that $\beta 2$-AR binding predicted premenstrual symptom severity.

Extending this line of evidence for the pathophysiological relevance of blunted myocardial reactivity in MRMD was our correlational analyses, albeit conducted in the full sample of women, showing that lower HR and CI stress reactivity predicted greater premenstrual 
depression, anxiety, and anger/irritability. Thus, the pattern of stress reactivity that differentiated MRMD from non-MRMD women was predictive of clinical symptomatology. This is consistent with the results of a recent longitudinal study in over 1,000 participants that showed lower HR reactivity to mental stress predicted greater depression severity scores over five years, even after controlling for baseline characteristics, medication use, and other potential confounds [78]. These investigators speculated that alterations in $\beta$-AR receptor mechanisms and/or vagal tone may mediate the link between blunted myocardial stress reactivity and the development of depressive illness. If this is the case, this could contribute to the association between a MRMD and the incident development of a major depressive disorder [16-18]. Although preliminary, replication of our findings for blunted myocardial stress reactivity predicting premenstrual symptoms could implicate SNS hypo-reactivity as a physiological mechanism mediating the link between MRMDs and the increased risk for the development of future depressive episodes [16-18].

Although we did not obtain statistical evidence that a history of depression, per se, is associated with blunted stress reactivity, that is not to say that such a history is not of relevance to the stress reactivity phenotype of women with a MRMD. Specifically, only in women who had no other depression history did we see blunted NE and DBP stress reactivity in MRMD women compared to women without a MRMD. Thus, a history of depression served to mask the generally hypoactive stress reactivity profile that we and others have previously reported in women with a MRMD. Examination of the mean DBP and NE reactivity data (Figures 4 and 5), suggests that this masking came about because of the generally blunted DBP and NE stress reactivity in non-MRMD women with prior depression (relative to never depressed non-MRMD women). Consequently, in women with a depression history, DBP and NE reactivity were roughly equivalent between MRMD and non-MRMD women. Nonetheless, these results contribute to the growing appreciation for the contextual role of psychiatric history in stress reactivity. For example, the presence or absence of a history of sexual abuse has been shown to differentially modify reactivity to challenge in women with a MRMD [10, 79]. Consequently, the lack of appreciation for the influence that historical context may have on stress reactivity may contribute to discrepancies in the literature on stress reactivity in women with a MRMD and other mood disorders.

The finding that a MRMD is associated with blunted SNS stress reactivity is not inconsistent with conceptualizations of MRMDs as a chronic disorder, despite time limited symptomatology. The cyclic recurrence of symptoms and a cyclic pathophysiologic trigger (unknown at present) persists for decades during a woman's reproductive years. While cardiovascular responses to stress are adaptive in the short-term, long-term activation of such responses due to repeated or chronic stress may lead to persistent dysregulation in stress responsive systems. In humans, the price of repeated biological adaptations to stress has been termed allostatic load, referring to the long-term effect of physiologic responses to stress [80]. Allostatic load, or dysregulation in stress responsive systems, may manifest in a variety of ways, including repeated elevations of neurohormonal stress mediators (e.g., norepinephrine) over long periods, as a failure to adapt to a stressor, as a failure to shut off the normal stress response, or as an inadequate response to stress [80, 81]. It has been suggested that such hypoactivation of stress responsive systems may result from a wearing out or exhaustion of the system due to longterm stress exposure and allostatic load [80]. Thus, chronic mood disorders may increase allostatic load in stress-responsive pathways, leading to long-term blunted sympathetic stress reactivity to even relatively mild stressors in the future. The clinical relevance of increased allostatic load comes from substantial evidence indicating that it is associated with increased risk for both cardiovascular disease and depression [see 82]. 
Lastly, both MRMD women and women with depression histories reported greater negative subjective responses to stress relative to their non-MRMD and never depressed counterparts. These results are unlikely to explain the stress reactivity differences since both MRMD women and women with a depression history endorsed greater difficulty with the tasks, and only those with both a depression history and MRMD reported greater tension (which would be expected to be associated with greater, and not lesser, stress reactivity). However, these results are consistent with a recent study showing heightened negative affect in response to stress in women with a history of depression [54]. If a history of depression increases the propensity to respond to stressors with greater negative affect or cognitive schemas, this could contribute to our findings for greater premenstrual functional impairment in women with a depression history relative to never depressed women. Since negative affect has been shown to predict the development of a future depressive episode in never-depressed individuals [83] as well as in those with a history of depression [84], altered affective regulation during stress may contribute to the greater likelihood of women with a MRMD experiencing future major depressive episodes [16-18]. If these findings are confirmed in longitudinal research, these results would suggest a potential therapeutic target for behavioral intervention that may decrease risk for stress-induced affective dysregulation in women with a history of depression and in women with a MRMD.

While this study has many notable strengths, including the use of strict diagnostic criteria based on a structured clinical interview and daily prospective ratings to establish the MRMD diagnoses, as well as a comprehensive assessment of stress-relevant SNS biomarkers, it is not without its limitations. First, although cycle phase was controlled for, the absence of follicular phase testing limits any interpretation about diagnostic-related differences in stress reactivity as a function of cycle phase. However, our prior research found blunted cardiovascular reactivity in MRMD women relative to non-MRMD women in both the follicular and luteal phases [21, 22]. A further limitation may be the possibility of a carryover effect from the pain testing [reported in 63] to the stress testing for measures of SNS stress reactivity. However, prior research from this laboratory in healthy non-MRMD and never depressed individuals did counterbalance the order of pain testing and mental stress testing using identical pain and stress tests employed in the present study, and found no evidence that the order of events influenced responses to either the pain test or the mental stress test [85]. Furthermore, by including a second baseline following pain testing it is unlikely that a carryover effect played a role in the results of the present study.

In conclusion, the present study indicates that women with a MRMD exhibit hypomyocardial reactivity to stress compared to women without a MRMD and that this blunted stress reactivity phenotype is predictive of greater premenstrual symptom severity. Although MRMD-related differences in DBP and NE stress reactivity were only statistically evident in women with no history of depression, this effect largely resulted from the generally blunted DBP and NE stress reactivity in the non-MRMD women with a history of depression. These findings underscore the relevance of psychiatric history to stress reactivity and suggest a potential mechanism (blunted stress reactivity) by which MRMD may increase the risk for the development of MDD [16-18]. Longitudinal studies designed to assess the ability of SNS hypo-reactivity to stress and heightened negative affect in response to stress to predict premenstrual symptoms as well as the incidence of major depressive disorder in women with a MRMD are indicated and would inform future intervention studies.

\section{Acknowledgments}

This research was supported by NIH grants RO1-MH051246 and CTRC grant CTSA UL1RR025747. 


\section{REFERENCES}

1. Kessler RC, Petukhova M, Sampson NA, Zaslavsky AM, Wittchen H. Twelve-month and lifetime prevalence and lifetime morbid risk of anxiety and mood disorders in the United States. Int J Methods Psychiatr Res. 2012; 21:169-184. [PubMed: 22865617]

2. Hartlage SA, Freels S, Gotman N, Yonkers K. Criteria for Premenstrual Dysphoric Disorder: secondary analyses of relevant data sets. Arch Gen Psychiatry. 2012; 69:300-305. [PubMed: 22393222]

3. Cunningham J, Yonkers KA, O'Brien S, Eriksson E. Update on research and treatment of premenstrual dysphoric disorder. Harv Rev Psychiatry. 2009; 17:120-137. [PubMed: 19373620]

4. Biggs WS, Demuth RH. Premenstrual syndrome and premenstrual dysphoric disorder. Am Fam Physician. 2011; 84:918-924. [PubMed: 22010771]

5. Halbreich U, Borenstein J, Pearlstein T, Kahn LS. The prevalence, impairment, impact, and burden of premenstrual dysphoric disorder (PMS/PMDD). Psychoneuroendocrinology. 2003; 28:1-23.

6. Pearlstein T, Steiner M. Premenstrual dysphoric disorder: burden of illness and treatment update. J Psychiatry Neurosci. 2008; 33:291-301. [PubMed: 18592027]

7. Freeman EW, Sondheimer SJ. Premenstrual Dysphoric Disorder: recognition and treatment. Prim Care Companion J Clin Psychiatry. 2003; 5:30-39. [PubMed: 15156244]

8. Wittchen HU, Becker E, Lieb R, Krause P. Prevalence, incidence and stability of premenstrual dysphoric disorder in the community. Psychol Med. 2002; 32:119-132. [PubMed: 11883723]

9. Bunevicius A, Leserman J, Girdler SS. Hypothalamic-pituitary-thyroid axis function in women with a menstrually related mood disorder: association with histories of sexual abuse. Psychosom Med. 2012; 74:810-816. [PubMed: 23001392]

10. Bunevicius R, Hinderliter AL, Light KC, Leserman J, Pedersen CA, Girdler SS. Histories of sexual abuse are associated with differential effects of clonidine on autonomic function in women with premenstrual dysphoric disorder. Biol Psychol. 2005; 69:281-296. [PubMed: 15925031]

11. Girdler SS, Sherwood A, Hinderliter AL, Leserman J, Costello NL, Straneva PA, Pedersen CA, Light KC. Biological correlates of abuse in women with premenstrual dysphoric disorder and healthy controls. Psychosom Med. 2003; 65:849-856. [PubMed: 14508031]

12. Cohen LS, Soares CN, Otto MW, Sweeney BH, Liberman RF, Harlow BL. Prevalence and predictors of premenstrual dysphoric disorder (PMDD) in older premenopausal women. The Harvard study of moods and cycles. J Affect Disord. 2002; 70:125-132. [PubMed: 12117624]

13. Pearlstein TB, Frank E, Rivera-Tovar A, Thoft JS, Jacobs E, Mieczkowski TA. Prevalence of axis I and axis II disorders in women with late luteal phase dysphoric disorder. J Affect Disord. 1990; 20:129-134. [PubMed: 2148327]

14. Yonkers KA. The association between premenstrual dysphoric disorder and other mood disorders. J Clin Psychiatry. 1997; 58:19-25. [PubMed: 9427873]

15. Harrison WM, Endicott J, Nee J, Glick H, Rabkin JG. Characteristics of women seeking treatment for premenstrual syndrome. Psychosomatics. 1989; 30:405-411. [PubMed: 2798733]

16. Hartlage SA, Arduino KE, Gehlert S. Premenstrual dysphoric disorder and risk for major depressive disorder: a preliminary study. J Clin Psychol. 2001; 57:1571-1578. [PubMed: 11745598]

17. Graze KK, Nee J, Endicott J. Premenstrual depression predicts future major depressive disorder. Acta Psychiatr Scand. 1990; 81:201-205. [PubMed: 2327284]

18. Roca CA, Schmidt PJ, Rubinow DR. A follow-up study of premenstrual syndrome. J Clin Psychiatry. 1999; 60:763-766. [PubMed: 10584765]

19. Kendler KS, Karkowski LM, Corey LA, Neale MC. Longitudinal population-based twin study of retrospectively reported premenstrual symptoms and lifetime major depression. Am J Psychiatry. 1998; 155:1234-1240. [PubMed: 9734548]

20. Endicott J, Amsterdam J, Eriksson E, Frank E, Freeman E, Hirschfeld R, Ling F, Parry B, Pearlstein T, Rosenbaum J, Rubinow D, Schmidt P, Severino S, Steiner M, Stewart DE, ThysJacobs S. Is premenstrual dysphoric disorder a distinct clinical entity? J Womens Health Gend Based Med. 1999; 8:663-679. [PubMed: 10839653] 
21. Girdler SS, Pedersen CA, Stern RA, Light KC. Menstrual cycle and premenstrual syndrome: modifiers of cardiovascular reactivity in women. Health Psychol. 1993; 12:180-192. [PubMed: 8500447]

22. Girdler SS, Pedersen CA, Straneva PA, Leserman J, Stanwyck CL, Benjamin S, Light KC. Dysregulation of cardiovascular and neuroendocrine responses to stress in premenstrual dysphoric disorder. Psychiatry Res. 1998; 81:163-178. [PubMed: 9858034]

23. Fontana AM, Badawy S. Perceptual and coping processes across the menstrual cycle: an investigation in a premenstrual syndrome clinic and a community sample. Behav Med. 1997; 22:152-159. [PubMed: 9138623]

24. Ravindran AV, Griffiths J, Waddell C, Anisman H. Stressful life events and coping styles in relation to dysthymia and major depressive disorder: variations associated with alleviation of symptoms following pharmacotherapy. Prog Neuropsychopharmacol Biol Psychiatry. 1995; 19:637-653. [PubMed: 8588062]

25. Kendler KS, Kuhn JW, Prescott CA. Childhood sexual abuse, stressful life events and risk for major depression in women. Psychol Med. 2004; 34:1475-1482. [PubMed: 15724878]

26. Morris MC, Ciesla JA, Garber J. A prospective study of stress autonomy versus stress sensitization in adolescents at varied risk for depression. J Abnorm Psychol. 2010; 119:341-354. [PubMed: 20455607]

27. Paddison PL, Gise LH, Lebovits A, Strain JJ, Cirasole DM, Levine JP. Sexual abuse and premenstrual syndrome: comparison between a lower and higher socioeconomic group. Psychosomatics. 1990; 31:265-272. [PubMed: 2388980]

28. Lee EE, Nieman LK, Martinez PE, Harsh VL, Rubinow DR, Schmidt PJ. ACTH and cortisol response to DEX/CRH testing in women with and without premenstrual dysphoria during GNRH agonist-induced hypogonadism and ovarian steroid replacement. Clin Endocrinol Metab. 2012; 97:1887-1896.

29. Chuong CJ, Coulam CB, Kao PC, Bergstralh EJ, Go VL. Neuropeptide levels in premenstrual syndrome. Fertil Steril. 1985; 44:760-765. [PubMed: 2934273]

30. Facchinetti F, Fioroni L, Martignoni E, Sances G, Costa A, Genazzani AR. Changes of opioid modulation of the hypothalamo-pituitary-adrenal axis in patients with severe premenstrual syndrome. Psychosom Med. 1994; 56:418-422. [PubMed: 7809341]

31. Giannini AJ, Martin DM, Turner CE. Beta-endorphin decline in late luteal phase dysphoric disorder. Int J Psychiatry Med. 1990; 20:279-284. [PubMed: 2265889]

32. Straneva PA, Maixner W, Light KC, Pedersen CA, Costello NL, Girdler SS. Menstrual cycle, betaendorphins, and pain sensitivity in premenstrual dysphoric disorder. Health Psychol. 2002; 21:358-367. [PubMed: 12090678]

33. Bancroft J, Cook A, Davidson D, Bennie J, Goodwin G. Blunting of neuroendocrine responses to infusion of L-tryptophan in women with perimenstrual mood change. Psychol Med. 1991; 21:305312. [PubMed: 1876635]

34. Su TP, Schmidt PJ, Danaceau M, Murphy DL, Rubinow DR. Effect of menstrual cycle phase on neuroendocrine and behavioral responses to the serotonin agonist m-chlorophenylpiperazine in women with premenstrual syndrome and controls. J Clin Endocrinol Metab. 1997; 82:1220-1228. [PubMed: 9100599]

35. Klatzkin RR, Lindgren ME, Forneris CA, Girdler SS. Histories of major depression and premenstrual dysphoric disorder: Evidence for phenotypic differences. Biol Psychol. 2010; 84:235-247. [PubMed: 20138113]

36. Girdler S, Klatzkin R. Biological responses to stress in premenstrual dysphoric disorder: influence of histories of abuse and depression. Gynaecology Forum. 2006; 11:27-32.

37. Gillespie CF, Nemeroff CB. Hypercortisolemia and depression. Psychosom Med. 2005; 67:S26S28. [PubMed: 15953796]

38. Holsboer F. The corticosteroid receptor hypothesis of depression. Neuropsychopharmacology. 2000; 23:477-501. [PubMed: 11027914]

39. Carney RM, Freedland KE, Veith RC, Cryer PE, Skala JA, Lynch T, Jaffe AS. Major depression, heart rate, and plasma norepinephrine in patients with coronary heart disease. Biol Psychiatry. 1999; 45:458-463. [PubMed: 10071718] 
40. Gold PW, Wong ML, Goldstein DS, Gold HK, Ronsaville DS, Esler M, Alesci S, Masood A, Licinio J, Geracioti TD Jr, Perini G, DeBellis MD, Holmes C, Vgontzas AN, Charney DS, Chrousos GP, McCann SM, Kling MA. Cardiac implications of increased arterial entry and reversible 24-h central and peripheral norepinephrine levels in melancholia. Proc Natl Acad Sci USA. 2005; 102:8303-8308. [PubMed: 15919819]

41. Hamer M, Tanaka G, Okamura H, Tsuda A, Steptoe A. The effects of depressive symptoms on cardiovascular and catecholamine responses to the induction of depressive mood. Biol Psychol. 2007; 74:20-25. [PubMed: 16860921]

42. Lake CR, Pickar D, Ziegler MG, Lipper S, Slater S, Murphy DL. High plasma norepinephrine levels in patients with major affective disorder. Am J Psychiatry. 1982; 139:1315-1318. [PubMed: 6289682]

43. Lechin F, van der Dijs B, Orozco B, Lechin ME, Baez S, Lechin AE, Rada I, Acosta E, Arocha L, Jimenez V, et al. Plasma neurotransmitters, blood pressure, and heart rate during supine-resting, orthostasis, and moderate exercise conditions in major depressed patients. Biol Psychiatry. 1995; 38:166-173. [PubMed: 7578659]

44. Udupa K, Sathyaprabha TN, Thirthalli J, Kishore KR, Lavekar GS, Raju TR, Gangadhar BN. Alteration of cardiac autonomic functions in patients with major depression: a study using heart rate variability measures. J Affect Disord. 2007; 100:137-141. [PubMed: 17113650]

45. Veith RC, Lewis N, Linares OA, Barnes RF, Raskind MA, Villacres EC, Murburg MM, Ashleigh EA, Castillo S, Peskind ER, et al. Sympathetic nervous system activity in major depression. Basal and desipramine-induced alterations in plasma norepinephrine kinetics. Arch Gen Psychiatry. 1994; 51:411-422. [PubMed: 8179465]

46. Volkers AC, Tulen JH, van den Broek WW, Bruijn JA, Passchier J, Pepplinkhuizen L. Motor activity and autonomic cardiac functioning in major depressive disorder. J Affect Disord. 2003; 76:23-30. [PubMed: 12943930]

47. Wong ML, Kling MA, Munson PJ, Listwak S, Licinio J, Prolo P, Karp B, McCutcheon IE, Geracioti TD Jr, DeBellis MD, Rice KC, Goldstein DS, Veldhuis JD, Chrousos GP, Oldfield EH, McCann SM, Gold PW. Pronounced and sustained central hypernoradrenergic function in major depression with melancholic features: relation to hypercortisolism and corticotropin-releasing hormone. Proc Natl Acad Sci USA. 2000; 97:325-330. [PubMed: 10618417]

48. Broadley AJ, Frenneaux MP, Moskvina V, Jones CJ, Korszun A. Baroreflex sensitivity is reduced in depression. Psychosom Med. 2005; 67:648-651. [PubMed: 16046382]

49. Bhagwagar Z, Hafizi S, Cowen PJ3. Increase in concentration of waking salivary cortisol in recovered patients with depression. Am J Psychiatry. 2003; 160:1890-1891. [PubMed: 14514508]

50. Vreeburg SA, Hoogendijk WJG, van Pelt J, DeRijk RH, Verhagen JCM, van Dyck R, Smit JH, Zitman FG, Penninx BWJH. Major depressive disorder and hypothalamic-pituitary-adrenal axis activity results from a large cohort study. Arch Gen Psychiatry. 2009; 66:617-626. [PubMed: 19487626]

51. Kathol RG. Persistent elevation of urinary free cortisol and loss of circannual periodicity in recovered depressive patients. A trait finding. J Affect Disord. 1985; 8:137-145. [PubMed: 3157722]

52. Young EA, Aggen SH, Prescott CA, Kendler KS. Similarity in saliva cortisol measures in monozygotic twins and the influence of past major depression. Biol Psychiatry. 2000; 48:70-74. [PubMed: 10913510]

53. Lok A, Mocking RJT, Ruhe' HG, Visser I, Koeter MWJ, Assies J, Bockting CLH, Olff M, Schene AH. Longitudinal hypothalamic-pituitary-adrenal axis trait and state effects in recurrent depression. Psychoneuroendocrinology. 2012; 37:892-902. [PubMed: 22094110]

54. Bagley SL, Weaver TL, Buchanan TW. Sex differences in physiological and affective responses to stress in remitted depression. Physiol Behav. 2011; 104:180-186. [PubMed: 21396947]

55. Girdler SS, Lindgren M, Porcu P, Rubinow DR, Johnson JL, Morrow AL. A history of depression in women is associated with an altered GABAergic neuroactive steroid profile. Psychoneuroendocrinology. 2012; 37:543-553. [PubMed: 21890277] 
56. Ahrens T, Deuschle M, Krumm B, van der Pompe G, den Boer JA, Lederbogen F. Pituitaryadrenal and sympathetic nervous system responses to stress in women remitted from recurrent major depression. Psychosom Med. 2008; 70:461-467. [PubMed: 18378864]

57. Morris MC, Rao U, Garber J. Cortisol responses to psychosocial stress predict depression trajectories: Social-evaluative threat and prior depressive episodes as moderators. J Affect Disord. 2012; 143:223-230. [PubMed: 22858210]

58. Endicott J, Nee J, Harrison W. Daily Record of Severity of Problems (DRSP): reliability and validity. Arch Womens Ment Health. 2006; 9:41-49. [PubMed: 16172836]

59. Rubinow DR, Roy-Byrne PP, Hoban MC, Gold PW, Post RM. Prospective assessment of menstrually related mood disorders. Am J Psychiatry. 1984; 141:684-686. [PubMed: 6538762]

60. Sheehan DV, Lecrubier Y, Sheehan KH, Amorim P, Janavs J, Weiller E, Hergueta T, Baker R, Dunbar GC. The Mini-International Neuropsychiatric Interview (M.I.N.I.): the development and validation of a structured diagnostic psychiatric interview for DSM-IV and ICD-0. J Clin Psychiatry. 1998; 59:22-33. [PubMed: 9881538]

61. Stoney CM, Owens JF, Matthews KA, Davis MC, Caggiula A. Influences of the normal menstrual cycle on physiologic functioning during behavioral stress. Psychophysiology. 1998; 27:125-135. [PubMed: 2247544]

62. Weidner G, Helmig L. Cardiovascular stress reactivity and mood during the menstrual cycle. Women Health. 1999; 16:5-21. [PubMed: 2267809]

63. Fleischman DS, Bunevicius A, Leserman J, Girdler SS. Menstrually related mood disorders and a history of abuse: moderators of pain sensitivity. Health Psychol. 2013 Mar 25. (Epub ahead of print).

64. Kirschbaum C, Pirke KM, Hellhammer DH. The 'Trier Social Stress Test'--a tool for investigating psychobiological stress responses in a laboratory setting. Neuropsychobiology. 1993; 28:76-81. [PubMed: 8255414]

65. Kirschbaum C, Klauer T, Filipp SH, Hellhammer DH. Sex-specific effects of social support on cortisol and participantive responses to acute psychological stress. Psychosom Med. 1995a; 57:2331. [PubMed: 7732155]

66. Kirschbaum C, Prussner JC, Stone AA, Federenko I, Gaab J, Lintz D, Schommer N, Hellhammer $\mathrm{DH}$. Persistent high cortisol responses to repeated psychological stress in a subpopulation of healthy men. Psychosom Med. 1995b; 57:468-474. [PubMed: 8552738]

67. Gronwall DM. Paced auditory serial-addition task: a measure of recovery from concussion. Percept Mot Skills. 1977; 44:367-373. [PubMed: 866038]

68. Dimsdale JE, Ziegler MG. What do plasma and urinary measures of catecholamines tell us about human response to stressors? Circulation. 1991; 83:36-42.

69. Sherwood A, Allen MT, Fahrenberg J, Kelsey RM, Lovallo WR, van Doornen LJP. Methodological guidelines for impedance cardiography. Psychophysiology. 1990; 27:1-23. [PubMed: 2187214]

70. Kubicek WG, Krnegis JN, Patterson RP, Witsoe DA, Mattson RH. Development an evaluation of impedance cardiac output system. Aerospace Medicine. 1996; 37:1208-1212. [PubMed: 5339656]

71. Blake F, Salkovskis P, Gath D, Day A, Garrod A. Cognitive therapy for premenstrual syndrome: a controlled trial. J Psychosom Res. 1998; 45:307-318. [PubMed: 9794277]

72. Schmidt PJ, Nieman LK, Danaceau MA, Adams LF, Rubinow DR. Differential behavioral effects of gonadal steroids in women with and in those without premenstrual syndrome. N. Engl J Med. 1998; 338:209-216. [PubMed: 9435325]

73. Foster PS, Goldie RG, Patterson JW. Effect of steroids on b-adrenoceptor-mediated relaxation of pig bronchus. Br J Pharmacol. 1983; 78:441-445. [PubMed: 6299446]

74. Heal DJ, Bristow LJ, DeSouza RJ, Bloomfield JG, Hurst EM, Elliott JM. The influence of injection of estradiol to female rats on changes in a2- and b-adrenoceptor function induced by repeated administration of desipramine or electroconvulsive shock. Neuropharmacology,. 1998; 27:1151-1159. [PubMed: 2849729]

75. Maggi A, Zucchi I, Perez J. Progesterone in rat brain: modulation of b-adrenergic receptor activity. Pharmacolog Res Commun. 1985; 17:283-291. 
76. Wheeldon NM, Newnham DM, Coutie WJ, Peters JA, McDevitt DG, Lipworth BJ. Influence of sex-steroid hormones on the regulation of lymphocyte beta 2-adrenoceptors during the menstrual cycle. Br J Clin Pharmacol. 1994; 37:583-588. [PubMed: 7917778]

77. Gurguis GN, Yonkers KA, Blakeley JE, Phan SP, Williams A, Rush AJ. Adrenergic receptors in premenstrual dysphoric disorder. II. Neutrophil beta2-adrenergic receptors: Gs protein coupling, phase of menstrual cycle and prediction of luteal phase symptom severity. Psychiatry Res. 1998; 79:31-42. [PubMed: 9676824]

78. Phillips AC, Hunt K, Der G, Carroll D. Blunted cardiac reactions to acute psychological stress predict symptoms of depression five years later: evidence from a large community study. Psychophysiology. 2011; 48:142-148. [PubMed: 20536905]

79. Girdler SS, Leserman J, Bunevicius R, Klatzkin R, Pedersen CA, Light KC. Persistent alterations in biological profiles in women with abuse histories: influence of premenstrual dysphoric disorder. Health Psychol. 2007; 26:201-213. [PubMed: 17385972]

80. McEwen BS. Stress, adaptation, and disease. Allostasis and allostatic load. Ann NY Acad Sci. 1998; 1:33-44. [PubMed: 9629234]

81. Siever LJ, Davis KL. Overview: toward a dysregulation hypothesis of depression. Am J Psychiatry. 1985; 142:1017-1031. [PubMed: 2862799]

82. Juster RP, McEwen BS, Lupien SJ. Allostatic load biomarkers of chronic stress and impact on health and cognition. Neurosci Biobehav Rev. 2010; 35:2-16. [PubMed: 19822172]

83. Robinson MS, Alloy LB. Negative cognitive styles and stress-reactive rumination interact to predict depression: a prospective study. Cognit Ther Res. 2003; 27:275-292.

84. Alloy LB, Abramson LY, Whitehouse WG, Hogan ME, Panzarella C, Rose DT. Prospective incidence of first onsets and recurrences of depression in individuals at high and low cognitive risk for depression. J Abnorm Psychol. 2006; 115:145-156. [PubMed: 16492105]

85. Mechlin MB, Maixner W, Light KC, Fisher JM, Girdler SS. African Americans show alterations in endogenous pain regulatory mechanisms and reduced pain tolerance to experimental pain procedures. Psychosom Med. 2005; 67:948-956. [PubMed: 16314600] 


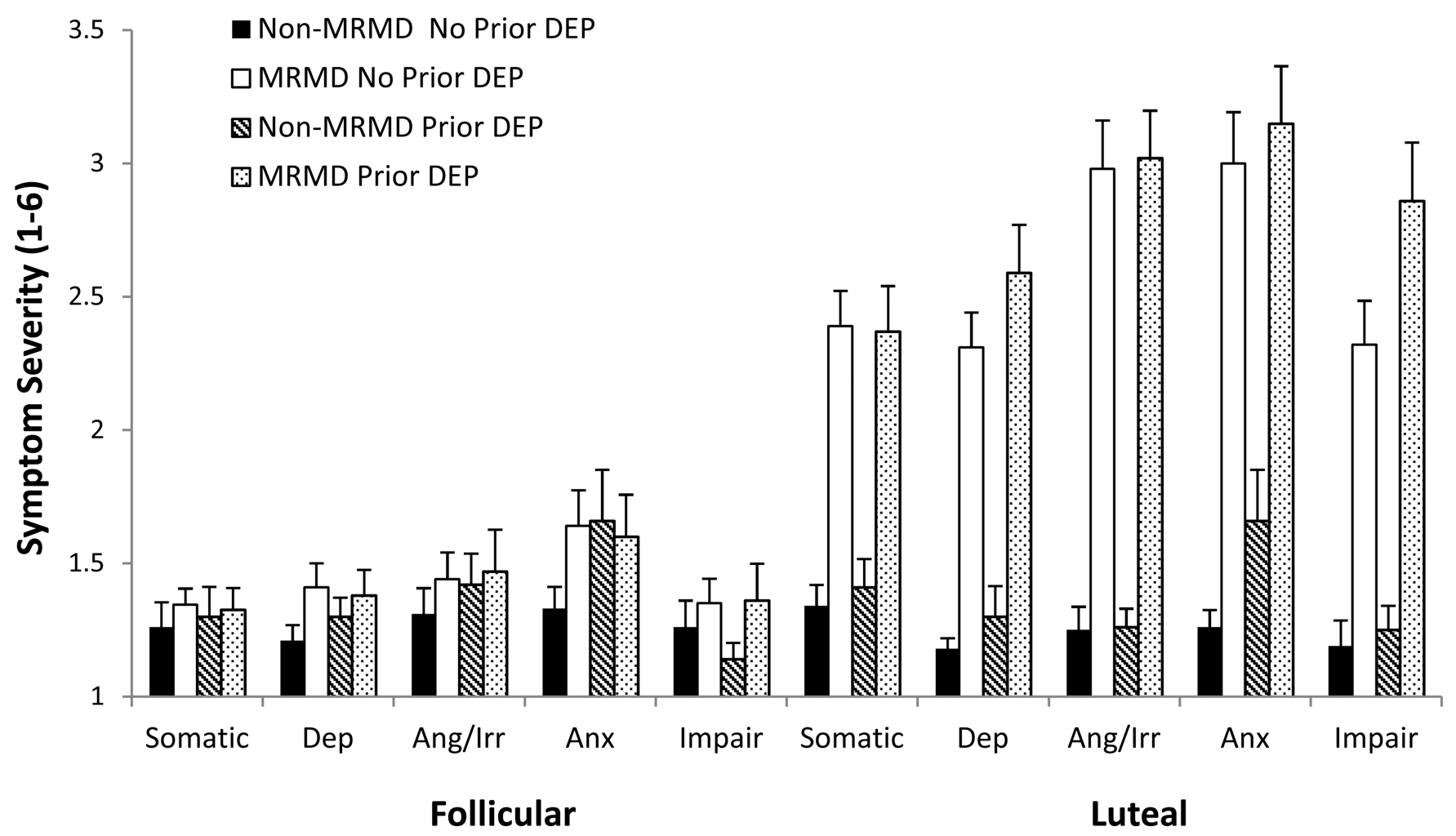

Fig. 1.

Mean $( \pm$ SEM) daily mood ratings core symptom categories as a function of MRMD and depression history status.

Dep = Depression; Ang/Irr = Anger/Irritability; Anx = Anxiety $;$ Impair = Impairment Prior Dep $=$ A history of major depressive disorder $(n=45)$ or dysthymia $(n=1)$. 


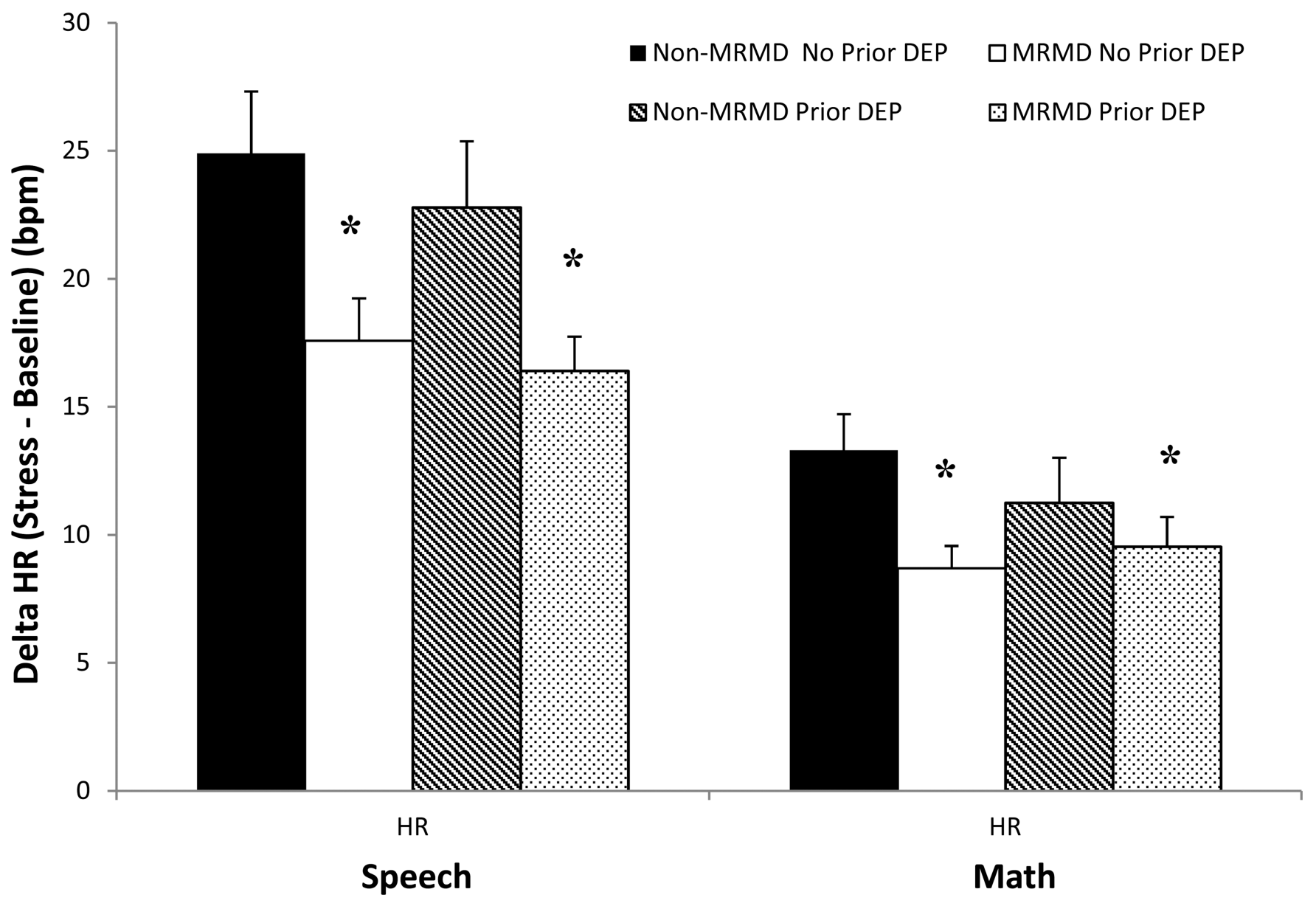

Fig 2.

Mean $( \pm$ SEM) change in heart rate (HR) from baseline to speech and math stress as a function of MRMD and depression history status.

$*$ MRMD $<$ non-MRMD, $\mathrm{p}<.01$

Prior Dep = A history of major depressive disorder $(n=45)$ or dysthymia $(n=1)$. 


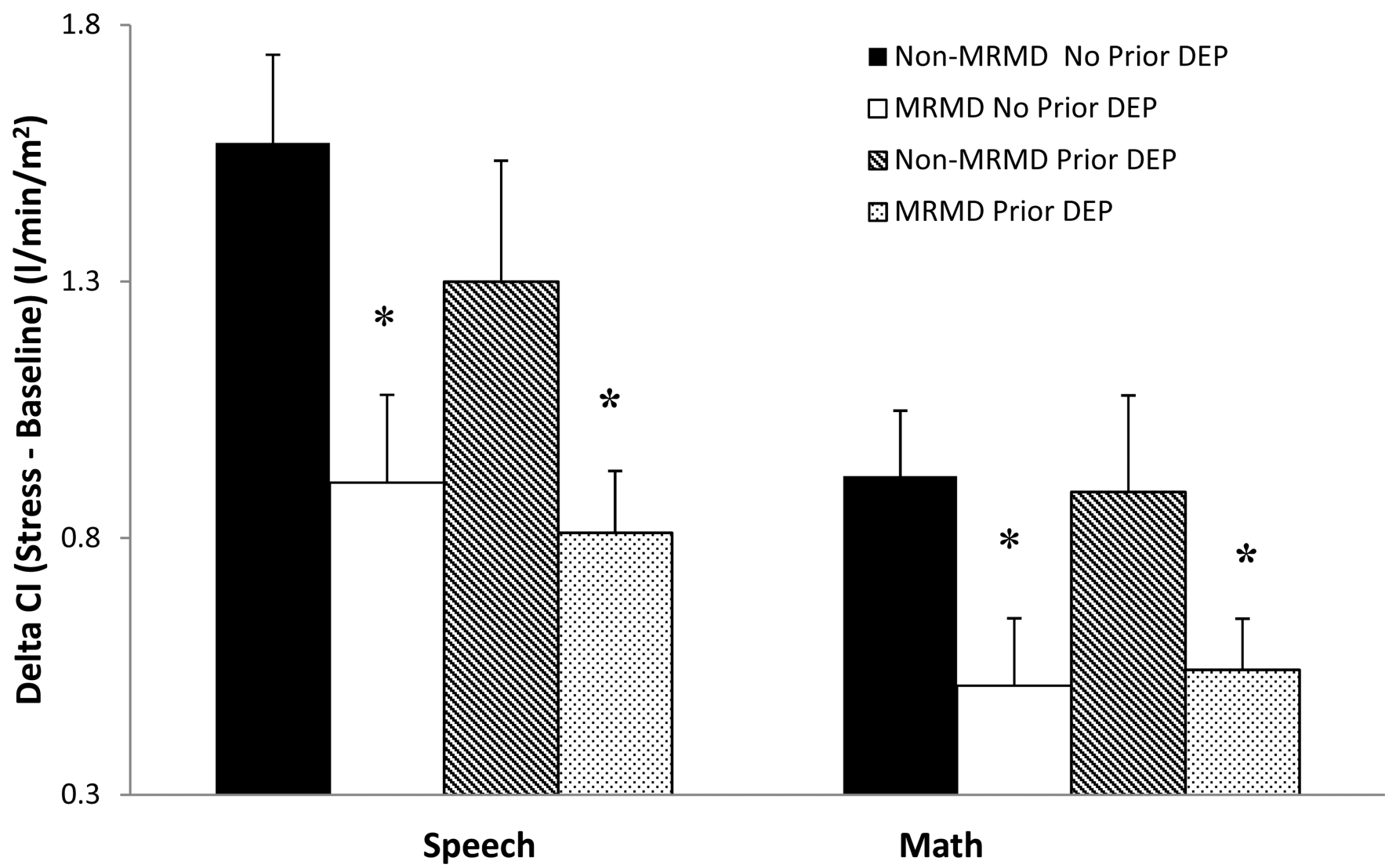

Fig 3.

Mean $( \pm \mathrm{SEM})$ change in cardiac index (CI) from baseline to speech and math stress as a function of MRMD and depression history status

*MRMD < non-MRMD, $\mathrm{p}<.01$

Prior Dep = A history of major depressive disorder $(n=45)$ or dysthymia $(n=1)$. 


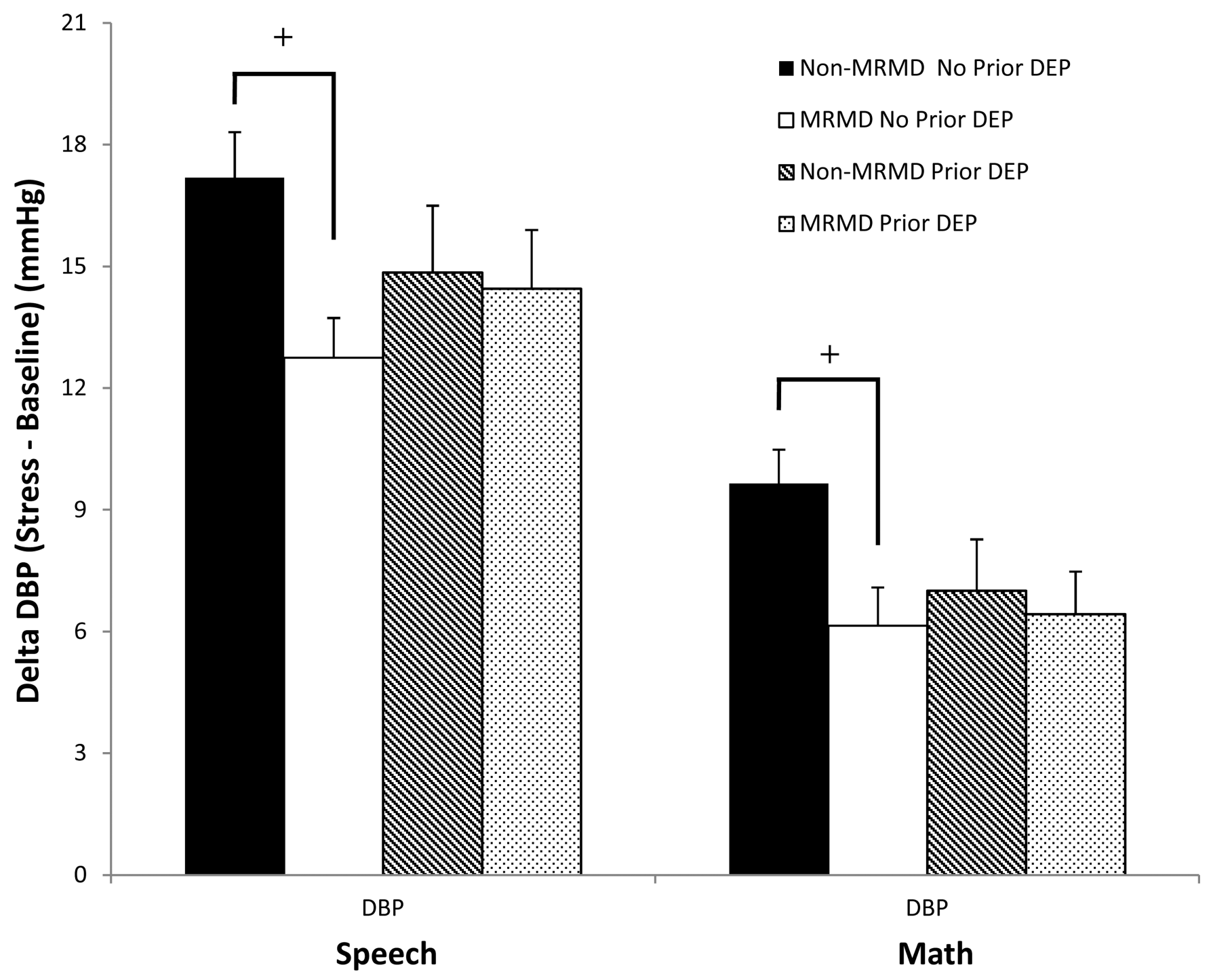

Fig 4.

Mean $( \pm$ SEM) change in diastolic blood pressure (DBP) from baseline to speech and math stress as a function of MRMD and depression history status.

${ }^{+} \mathrm{MRMD} \times$ History of depression interaction, $\mathrm{p}=.09 ; \mathrm{MRMD}<$ non-MRMD only in no prior depression, $\mathrm{p}<.01$

Prior Dep $=$ A history of major depressive disorder $(n=45)$ or dysthymia $(n=1)$. 


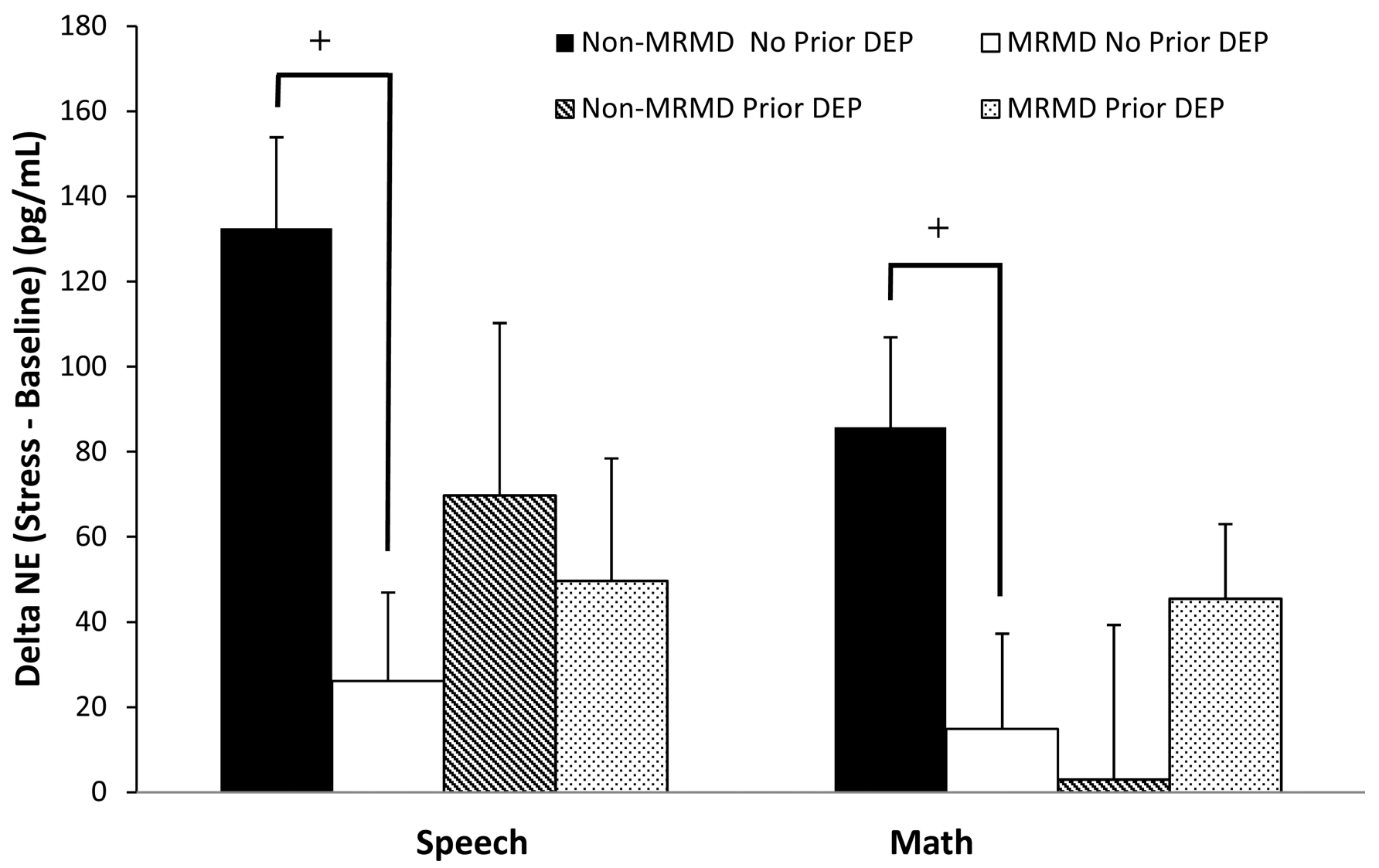

Fig 5.

Mean $( \pm$ SEM) change in norepinephrine (NE) from baseline to speech and math stress as a function of MRMD and depression history status.

${ }^{+} \mathrm{MRMD} \times$ History of depression interaction, $\mathrm{p}<.05 ; \mathrm{MRMD}<$ non-MRMD only in no prior depression, $\mathrm{p}<.01$

Prior Dep $=$ A history of major depressive disorder $(n=45)$ or dysthymia $(n=1)$. 


\section{Table I}

Mean $( \pm$ SEM) baseline and demographic factors as a function of MRMD and Depression History

\begin{tabular}{|c|c|c|c|c|}
\hline & $\begin{array}{l}\text { Non-MRMD } \\
\text { Never Depressed } \\
(\mathrm{n}=43)\end{array}$ & $\begin{array}{l}\text { Non-MRMD } \\
\text { Depression History } \\
(\mathbf{n = 2 0})\end{array}$ & $\begin{array}{l}\text { MRMD } \\
\text { Never Depressed } \\
(\mathbf{n}=37)\end{array}$ & $\begin{array}{l}\text { MRMD } \\
\text { Depression } \\
\text { History } \\
(\mathbf{n = 2 6})\end{array}$ \\
\hline Age (years) & $34.4( \pm 1.24)$ & $34.0( \pm 1.97)$ & $33.1( \pm 1.27)$ & $35.3( \pm 1.52)$ \\
\hline Body Mass Index & $24.7( \pm 0.86)$ & $27.2( \pm 1.61)$ & $27.7( \pm 0.96)$ & $26.2( \pm 1.34)$ \\
\hline Beck Depression Inventory $A$ & $1.86( \pm 0.36)$ & $3.14( \pm 0.76)$ & $7.51( \pm 1.15)$ & $7.57( \pm 1.23)$ \\
\hline State Anxiety ${ }^{A}$ & $27.4( \pm 1.17)$ & $28.9( \pm 1.97)$ & $31.5( \pm 1.33)$ & $33.3( \pm 1.66)$ \\
\hline Months in remission from depression & NA & $66.8( \pm 9.70)$ & NA & $106.9( \pm 20.0)$ \\
\hline No. (\%) Minority Race & $21(49 \%)$ & $5(25 \%)$ & $13(35 \%)$ & $9(35 \%)$ \\
\hline No. (\%) History of anxiety disorders $B$ & $7(16 \%)$ & $10(50 \%)$ & $8(22 \%)$ & $14(54 \%)$ \\
\hline No. (\%) History of substance abuse ${ }^{B}$ & $2(5 \%)$ & $6(30 \%)$ & $3(11 \%)$ & $8(31 \%)$ \\
\hline No. $(\%)$ History of suicidality $B$ & $1(2 \%)$ & $7(35 \%)$ & $4(11 \%)$ & $11(42 \%)$ \\
\hline No. (\%) History of eating disorders & $1(2 \%)$ & $0(0 \%)$ & $1(3 \%)$ & $4(15 \%)$ \\
\hline
\end{tabular}

\footnotetext{
${ }^{A}$ MRMD $>$ non-MRMD; $\mathrm{p} \leq .01$

${ }^{B}$ Histories of depression $>$ no histories of depression; ps $<.05$
} 


\section{Table II}

Mean ( \pm SEM) baseline cardiovascular and plasma norepinephrine levels at rest and, for measures with nonsignificant group differences, in response to stress, as a function of MRMD and Depression History

\begin{tabular}{|c|c|c|c|c|}
\hline & $\begin{array}{l}\text { Non-MRMD } \\
\text { Never Depressed } \\
(\mathrm{n}=42)\end{array}$ & $\begin{array}{l}\text { Non-MRMD } \\
\text { Depression History } \\
(\mathbf{n = 2 0})\end{array}$ & $\begin{array}{l}\text { MRMD } \\
\text { Never Depressed } \\
(\mathbf{n}=36)\end{array}$ & $\begin{array}{l}\text { MRMD } \\
\text { Depression History } \\
(\mathbf{n = 2 5})\end{array}$ \\
\hline Systolic Blood Pressure (mmHg) & $115.5( \pm 1.96)$ & $111.0( \pm 2.0) C$ & $111.6( \pm 2.01)^{E}$ & $113.1( \pm 2.62)$ \\
\hline Diastolic Blood Pressure (mmHg) & $68.9( \pm 1.35)$ & $67.4( \pm 2.17) C$ & $69.3( \pm 1.29)^{E}$ & $67.6( \pm 1.90)$ \\
\hline Heart Rate (bpm) & $66.7( \pm 1.64)$ & $65.7( \pm 2.99)$ & $64.6( \pm 1.62)$ & $67.5( \pm 1.60)$ \\
\hline Cardiac Index $\left(\mathrm{L} / \mathrm{min} / \mathrm{m}^{2}\right)$ & $3.7( \pm 0.17)$ & $3.3( \pm 0.19)^{B}$ & $3.5( \pm 0.15)$ & $3.7( \pm 0.18)$ \\
\hline $\begin{array}{l}\text { Total Peripheral Resistance Index (dynes*sec/ } \mathrm{cm}^{5} / \\
\mathrm{m}^{2} \text { ) }\end{array}$ & $2070.7( \pm 156.8)$ & $3867.5( \pm 1887.5) C$ & $2183.6( \pm 149.8)^{E}$ & $1972.3( \pm 151.0)$ \\
\hline Stroke Volume Index $\left(\mathrm{mL} / \mathrm{beat} / \mathrm{m}^{2}\right)$ & $57.1( \pm 3.11)$ & $50.3( \pm 4.34)$ & $55.3( \pm 4.14)$ & $55.1( \pm 3.17)$ \\
\hline Norepinephrine (pg/mL) & $354.6( \pm 17.7)$ & $350.2( \pm 29.5)^{B}$ & $325.2( \pm 23.6)^{E}$ & $332.7( \pm 38.7)^{F}$ \\
\hline Delta Speech Systolic Blood Pressure (mmHg) & $24.89( \pm 1.75)$ & $22.23( \pm 3.10) D$ & $22.13( \pm 1.88)^{E}$ & $21.86( \pm 2.18)$ \\
\hline Delta Math Systolic Blood Pressure (mmHg) & $14.84( \pm 1.36)$ & $13.5( \pm 2.4) C$ & $10.73( \pm 1.44) E$ & $12.6( \pm 1.69)$ \\
\hline $\begin{array}{l}\text { Delta Speech Total Peripheral Resistance Index } \\
\left(\text { dynes* }{ }^{*} \mathrm{sec} / \mathrm{cm}^{5} / \mathrm{m}^{2} \text { ) }\right.\end{array}$ & $-193.8( \pm 48.8)$ & $-218.5( \pm 79.3) D$ & $-91.0( \pm 53.4) E$ & $-99.0( \pm 82.4)$ \\
\hline $\begin{array}{l}\text { Delta Math Total Peripheral Resistance Index } \\
\left(\text { dynes* }{ }^{*} \mathrm{sec} / \mathrm{cm}^{5} / \mathrm{m}^{2}\right)\end{array}$ & $-110.1( \pm 37.4)^{A}$ & $-175.9( \pm 66.3) C$ & $-62.3( \pm 46.6)^{E}$ & $-117.8( \pm 47.6)$ \\
\hline Delta Speech Stroke Volume Index (mL/beat $\left./ \mathrm{m}^{2}\right)$ & $1.07( \pm 1.38)$ & $-0.52( \pm 2.12) B$ & $-0.17( \pm 1.36)$ & $-0.096( \pm 1.27)$ \\
\hline Delta Math Stroke Volume Index (mL/beat $\left./ \mathrm{m}^{2}\right)$ & $1.15( \pm 1.28)^{A}$ & $2.41( \pm 1.4)$ & $0.78( \pm 0.93)$ & $1.29( \pm 1.13)$ \\
\hline
\end{tabular}

$A_{\mathrm{n}=41}$

$B_{\mathrm{n}=19}$

$C_{\mathrm{n}=18}$

$D_{\mathrm{n}=17}$

$E_{\mathrm{n}=35}$

$F_{\mathrm{n}=23}$ 